\title{
WALL TRANSPIRATION EFFECTS ON DEVELOPING MIXED CONVECTION HEAT TRANSFER IN INCLINED RECTANGULAR DUCTS
}

Jer-Huan Jang

Department of Mechanical Engineering, Ming Chi University of Technology, Taishan, Taipei County, Taiwan 243, R.O.C, jhjang@mail.mcut.edu.tw

Han-Chieh Chiu

Department of Mechanical Engineering, Technology and Science Institute of Northern Taiwan, Pei-To, Taipei, Taiwan 112, R.O.C.

Wei-Mon Yan

Graduate Institute of Greenergy Technology, National University of Tainan, Tainan, Taiwan 700, R.O.C

Follow this and additional works at: https://jmstt.ntou.edu.tw/journal

Part of the Engineering Commons

\section{Recommended Citation}

Jang, Jer-Huan; Chiu, Han-Chieh; and Yan, Wei-Mon (2010) "WALL TRANSPIRATION EFFECTS ON DEVELOPING MIXED CONVECTION HEAT TRANSFER IN INCLINED RECTANGULAR DUCTS," Journal of Marine Science and Technology. Vol. 18: Iss. 2, Article 11.

DOI: $10.51400 / 2709-6998.2324$

Available at: https://jmstt.ntou.edu.tw/journal/vol18/iss2/11

This Research Article is brought to you for free and open access by Journal of Marine Science and Technology. It has been accepted for inclusion in Journal of Marine Science and Technology by an authorized editor of Journal of Marine Science and Technology. 
WALL TRANSPIRATION EFFECTS ON DEVELOPING MIXED CONVECTION HEAT TRANSFER IN INCLINED RECTANGULAR DUCTS

\section{Acknowledgements}

The authors would like to acknowledge the financial support of the present work by the National Science Council, R.O.C. through the contract NSC93-2212-E211-011 and NSC95-2221-E149-012. The support from Technology and Science Institute of Northern Taiwan is also acknowledged. 


\title{
WALL TRANSPIRATION EFFECTS ON DEVELOPING MIXED CONVECTION HEAT TRANSFER IN INCLINED RECTANGULAR DUCTS
}

\author{
Jer-Huan Jang*, Han-Chieh Chiu**, and Wei-Mon Yan***
}

Key words: wall transpiration, developing mixed convection, inclined rectangular ducts.

\begin{abstract}
The developing mixed convection heat transfer in inclined rectangular ducts with wall transpiration effects has been investigated numerically in detail. The three-dimensional Navier-Stokes equations and energy equation are solved simultaneously with the vorticity- velocity method. For a given combination of governing parameters wall Reynolds number, $\operatorname{Re}_{\mathrm{w}}$, aspect ratio $\gamma$, modified Rayleigh number, $R a^{*}$, and mixed convection parameter, $\Omega$, the solution is evaluated by a marching technique. The effects of wall transpiration and the inclination angle on the distributions of the bulk fluid temperature, the local averaged friction factor and Nusselt number are emphasized in detail. Both conditions of uniform heat flux and wall temperature have been analyzed. Results indicate that increasing inclination angle contributes more buoyancy convection in axial direction and results in higher fRe and $\mathrm{Nu}$. The heat transfer of suction is larger than that of injection. However, the behavior of friction factor shows the opposite trend.
\end{abstract}

\section{INTRODUCTION}

Mixed convection flows arise in many transport processes in natural and engineering devices. Atmospheric boundary layer flow, heat exchangers, solar collectors, nuclear reactors, and electronic equipments are some examples. Such a process occurs when the effect of the buoyancy force in forced convection or the effect of forced flow in free convection becomes significant. In the study of internal flows of mixed convection

Paper submitted 09/26/08; revised 06/06/09; accepted 06/08/09. Author for correspondence: Jer-Huan Jang (e-mail: jhjang@mail.mcut.edu.tw).

*Department of Mechanical Engineering, Ming Chi University of Technology, Taishan, Taipei County, Taiwan 243, R.O.C.

**Department of Mechanical Engineering, Technology and Science Institute of Northern Taiwan, Pei-To, Taipei, Taiwan 112, R.O.C.

***Graduate Institute of Greenergy Technology, National University of Tainan, Tainan, Taiwan 700, R.O.C. heat transfer, the interactions of thermal and hydrodynamic development become fairly complicated. For vertical ducts, the gravity force acts in the main flow direction, and there will be no secondary flow in the cross section. As for horizontal ducts, the buoyancy force is normal to the main flow direction and induces secondary flows in the cross plane. However, buoyancy force acts in both main flow and the cross-stream direction in inclined ducts,. Many works have been investigated on mixed heat transfer in laminar or turbulent flows in vertical and horizontal rectangular ducts [3-5, 7, 10-13, 23-24]. However, different orientations of the channel are able to induce different kinds of heat buoyant flows which enhance the heat transfer in different manners. Yan [25] has studied numerically on the transport phenomena of mixed convection heat and mass transfer in an inclined rectangular duct. $\mathrm{He}$ found that the buoyancy forces distort the velocity, temperature and concentration distributions. Huang and Lin [6] investigated the transient mixed convection air flow in a bottom heated inclined rectangular duct. Attention was particularly paid to delineate the effects of the duct inclination on the flow transition with heat transfer only. Recently, the investigation of mixed convection heat transfer enhancement through film evaporation in inclined square ducts has been numerically examined by Jang et al. [9]. They found that friction factor, heat and mass transfer are affected considerably by the inclination angle of the duct, especially for a lower inclination angle.

The fluid flow in the channel with porous wall has long been investigated in many engineering applications. The study of steady flow in a straight channel with porous walls could be traced back to Berman's work [1]. In this study, he gave a series solution for the laminar two-dimensional flow between two parallel porous plane walls driven by uniform injection and suction. Terrill [21, 22] gave an exact series solution for the fully-developed laminar flow in a pipe of circular cross section with porous wall driven by a spatially variable although time independent suction and/or injection. Studies on developing flow in porous-walled ducts with suction and injection effects were carried out by Raithby and Knudsen [17] and Sorour et al. [20]. The thermal entrance heat transfer with fully-developed velocity distributions in porous ducts was carried out by Pederson and Kinney [15] and 
Raithby [16]. Later, Yan and his colleague [26-28] investigated effects of wall transpiration on mixed convection heat transfer with rotating channel or rotating disks. Recently, Oyewola [14] experimentally studied wall suction effect on a turbulent flow. He found that effect of suction is significant on skewness than on flatness factor in the near-wall region. Ishak et al. [8] numerically investigated the effects of transpiration on the steady mixed convection flow over a vertical slender cylinder. They discovered that suction delays the boundary separation, while injection accelerates it. Erdoğan and İmrak [2] examined the effects of the side walls on the flow in ducts with suction and injection. However, it is a non-Newtonian fluid flow.

It is noted that the study of developing mixed convection flow in inclined ducts with transpiration is useful in practical sense, but it has not received enough attention and the studies of developing mixed convection flow in inclined ducts with transpiration have never been investigated. The aim of this study is to investigate the transpiration effects on the developing mixed convection flow in inclined rectangular ducts.

\section{ANALYSIS}

\section{Problem Statement}

The geometry of this problem as schematically shown in Fig. 1 is a rectangular duct with inclination angle $\Theta$, width $a$, and height $b$. The velocity components in $\mathrm{x}, \mathrm{y}$, and $\mathrm{z}$ directions are denoted as $u, v$, and $w$, respectively. A uniform axial velocity $w_{o}$ and a uniform temperature $T_{o}$ are imposed at the inlet $\mathrm{z}=0$. Although practical flows are often turbulent, the entering upward flow is assumed to be steady and laminar. The temperature of the injected or suctioned fluid is the same as that of the duct wall. The walls are imposed uniform and constant heat flux (UHF) or temperature (UWT), $\mathrm{T}_{\mathrm{w}}$. The viscous dissipations and compression effect in the energy equation are neglected since Mach number is low. The fluid thermophysical properties are taken to be constant except for the density variation in the buoyancy terms of the $y$ - and z-direction momentum equations. The Boussinesq approximation is employed for the thermal buoyancy effect.

\section{Governing Equations}

With descriptions of the problem and the assumptions above, the governing equations which are those of conservation of mass, momentum, and energy. Introducing the dimensionless parameters in the following:

$$
\begin{gathered}
D_{e}=4 A / s \quad X=x / D e \quad Y=y / D e \quad Z=z /(D e \cdot \operatorname{Re}) \\
Z^{*}=Z / \operatorname{Pr} \quad U=u D e / v \quad V=v D e / v \quad W=w / w_{o} \\
\bar{P}=\bar{p} /\left(\rho_{o} w^{2}\right) \quad P^{\prime}=p^{\prime} /\left(\rho_{0} v^{2} / D e^{2}\right) \quad \gamma=a / b \\
\operatorname{Re}=w_{o} D_{e} / v \quad \operatorname{Re}_{w}=v_{i n} D_{e} / v \quad R a=\operatorname{Pr} \cdot G r
\end{gathered}
$$
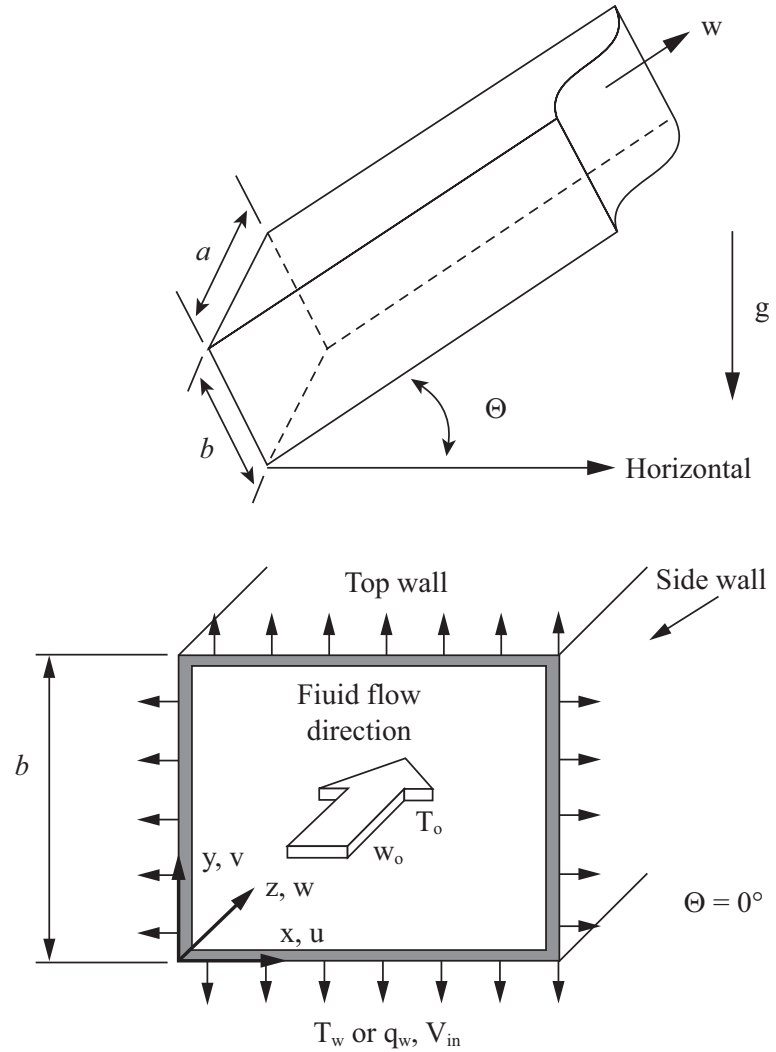

Fig. 1. Schematic diagram of the physical system.

$$
\begin{gathered}
\operatorname{Pr}=v / \alpha \quad G r=g \beta \Delta T D_{e}^{3} / v^{2} \quad R a^{*}=R a \cdot \cos \Theta \\
\Omega=(R a / \mathrm{Re}) \sin \Theta \quad \theta=\left(T-T_{o}\right) / \Delta T, \\
\Delta T=q_{w} D_{e} / k \text { for UHF or } T_{w}-T_{o} \text { for UWT }
\end{gathered}
$$

The non-dimensional governing equations can be formulated as follows:

\section{Continuity equation}

$$
\frac{\partial U}{\partial X}+\frac{\partial V}{\partial Y}+\frac{\partial W}{\partial Z}=0
$$

Momentum equations of $X, Y, Z$ directions

$$
U \frac{\partial U}{\partial X}+V \frac{\partial U}{\partial Y}+W \frac{\partial U}{\partial Z}=-\frac{\partial P^{\prime}}{\partial X}+\frac{\partial^{2} U}{\partial X^{2}}+\frac{\partial^{2} U}{\partial Y^{2}}
$$

$$
U \frac{\partial V}{\partial X}+V \frac{\partial V}{\partial Y}+W \frac{\partial V}{\partial Z}=-\frac{\partial P^{\prime}}{\partial Y}+\frac{\partial^{2} V}{\partial X^{2}}+\frac{\partial^{2} V}{\partial Y^{2}}+\frac{R a \cos \Theta}{\operatorname{Pr}} \cdot \theta
$$

$U \frac{\partial W}{\partial X}+V \frac{\partial W}{\partial Y}+W \frac{\partial W}{\partial Z}=-\frac{\partial \bar{P}}{\partial Z}+\frac{\partial^{2} W}{\partial X^{2}}+\frac{\partial^{2} W}{\partial Y^{2}}+\frac{\Omega}{\operatorname{Pr}} \cdot \theta$ 
Energy equation

$$
U \frac{\partial \theta}{\partial X}+V \frac{\partial \theta}{\partial Y}+W \frac{\partial \theta}{\partial Z}=\frac{1}{\operatorname{Pr}}\left[\frac{\partial^{2} \theta}{\partial X^{2}}+\frac{\partial^{2} \theta}{\partial Y^{2}}\right]
$$

The non-dimensional axial vorticity is introduced as

$$
\xi=\frac{\partial U}{\partial Y}-\frac{\partial V}{\partial X}
$$

The axial vorticity transport equation can then be derived through operation of (3) and (4) as follows.

$$
\begin{aligned}
U \frac{\partial \xi}{\partial X} & +V \frac{\partial \xi}{\partial Y}+W \frac{\partial \xi}{\partial Z}+\xi\left(\frac{\partial U}{\partial X}+\frac{\partial V}{\partial Y}\right)+\left(\frac{\partial W}{\partial Y} \cdot \frac{\partial U}{\partial Z}-\frac{\partial W}{\partial X} \cdot \frac{\partial V}{\partial Z}\right) \\
& =\frac{\partial^{2} \xi}{\partial X^{2}}+\frac{\partial^{2} \xi}{\partial Y^{2}}-\frac{(R a \cos \Theta)}{\operatorname{Pr}} \cdot \frac{\partial \theta}{\partial X}
\end{aligned}
$$

The continuity equation can be reformulated as

$$
\begin{gathered}
\frac{\partial^{2} U}{\partial X^{2}}+\frac{\partial^{2} U}{\partial Y^{2}}=\frac{\partial \xi}{\partial Y}-\frac{\partial^{2} W}{\partial X \partial Z} \\
\frac{\partial^{2} V}{\partial X^{2}}+\frac{\partial^{2} V}{\partial Y^{2}}=-\frac{\partial \xi}{\partial X}-\frac{\partial^{2} W}{\partial Y \partial Z}
\end{gathered}
$$

In this study, an additional equation is necessary to solve the pressure gradient term in the axial momentum equation. The overall mass balance equation at each axial location is utilized to serve this purpose and expressed as the following:

$$
\bar{W}=1-2 \operatorname{Re}_{w} \frac{(1+\gamma)^{2}}{\gamma} Z
$$

The wall Reynolds number $\mathrm{Re}_{\mathrm{w}}$ is defined based on the injection or suction velocity $v_{\text {in }}$. The value of $\mathrm{Re}_{\mathrm{w}}$ is positive for wall suction and negative for wall injection.

\section{Boundary Conditions}

The corresponding boundary conditions for the inlet and the side walls are:

At the entrance $(Z=0)$ :

$$
W=1 ; U=V=\xi=0, \theta=0
$$

On the left wall $(X=0)$ :

$$
W=V=0, U=-\operatorname{Re}_{w}, \partial \theta / \partial X=-1 \quad(\text { for } \mathrm{UHF})
$$

On the right wall $X=(1+\gamma) / 2$ :

$$
\begin{array}{r}
W=V=0, U=\mathrm{Re}_{w}, \quad \partial \theta / \partial X=1 \quad(\text { for } \mathrm{UHF}) \\
\theta=1(\text { for UWT) }
\end{array}
$$

On the bottom wall $Y=0$ :

$$
\begin{aligned}
W=U=0, V=-\mathrm{Re}_{w}, \partial \theta / \partial Y=-1 & (\text { for UHF) } \\
\theta=1 & (\text { for UWT })
\end{aligned}
$$

On the top wall $Y=(1+\gamma) /(2 \gamma)$ :

$$
W=U=0, V=\operatorname{Re}_{w}, \partial \theta / \partial Y=1 \quad(\text { for } \mathrm{UHF})
$$$$
\theta=1(\text { for } \mathrm{UWT})(16)
$$

The governing equations contain dimensionless parameters $\Omega, R a^{*}, \gamma$, and $\operatorname{Pr}$, as defined in (2) The value of $\Omega$ is a mixed convection parameter, i.e. the ratio of Raleigh number $R a$ to the Reynolds number Re, and modified by an inclination angle factor $\sin \Theta$. In addition, $R a^{*}=R a \cos \Theta$ is modified Rayleigh number. The inclination angle does not appear explicitly with the introduction of the independent parameters $\Omega$ and $R a^{*}$. Apparently, for a horizontal duct,

$$
\Theta=0, \quad \sin \Theta=0, R a^{*}=R a, \quad \Omega=0
$$

while for a vertical duct,

$$
\Theta=\pi / 2, \sin \Theta=1, \quad R a^{*}=0, \Omega=R a / \operatorname{Re}
$$

After obtaining the developing velocity and temperature fields along the axial direction of the rectangular duct, the local friction factor and Nusselt numbers are major parameters of practical interest for the study of mixed convection heat transfer. According to usual definitions, the expression for the product of the circumferentially averaged friction factor and Reynolds number are expressed as

$$
f \operatorname{Re}=-\left.2 \frac{\overline{\partial W}}{\partial n}\right|_{\text {wall }}
$$

where the overbar represents the circumferential average value and $n$ denotes the dimensionless coordinate normal to the duct wall.

The local averaged Nusselt number on the duct wall can be written as

$$
\begin{gathered}
N u=\frac{1}{\theta_{w}-\theta_{b}} \text { for UHF } \\
N u=\frac{(\overline{\partial \theta / \partial \mathrm{n}})_{\mathrm{w}}}{1-\theta_{b}} \text { for UWT }
\end{gathered}
$$

where the over bar means the average value around the pe- 
rimeters.

In the above equations, the bulk fluid temperature $\theta_{b}$ is defined as

$$
\theta_{b}=\frac{\int_{0}^{\frac{1+\gamma}{2 \gamma}} \int_{0}^{\frac{1+\gamma}{2}} \theta \cdot W d X d Y}{\int_{0}^{\frac{1+\gamma}{2 \gamma}} \int_{0}^{\frac{1+\gamma}{2}} W d X d Y}
$$

\section{SOLUTION METHOD}

The equations for the unknown $U, V, W, \theta$, and $d \bar{P} / d Z$ are coupled, and the vorticity-velocity method for three-dimensional parabolic flow [18] is employed to solve the governing equations. A marching technique based on the DuFort-Frankel scheme [19] is utilized to solve the fields for a given combination of parameters. The grid distributions were arranged to be uniform in the cross-sectional plane. To obtain accurate velocity and temperature fields in the entrance region, the grid in the axial direction is set non-uniform. The independence of the grid resolution of numerical results is checked with a numerical experiment. Various grid distributions in the crosssectional plane $(M \times N)$ and axial step size $\left(\Delta Z^{*}\right)$ were set. There are four grid distributions tested in the analysis. They are $31 \times 31\left(1 \times 10^{-5} \sim 2 \times 10^{-4}\right), 51 \times 51\left(1 \times 10^{-5} \sim 2 \times 10^{-4}\right), 51 \times$ $51\left(1 \times 10^{-6} \sim 2 \times 10^{-4}\right)$, and $81 \times 81\left(1 \times 10^{-5} \sim 2 \times 10^{-4}\right)$, respectively. It is found that the deviations in local averaged Nusselt number $\mathrm{Nu}$ calculated with $51 \times 51\left(\Delta \mathrm{Z}^{*}=1 \times 10^{-5} \sim 2\right.$ $\left.\times 10^{-4}\right)$ and $81 \times 81\left(1 \times 10^{-5} \sim 2 \times 10^{-4}\right)$ are always less than $2 \%$. Furthermore, the deviations in Nu calculated with $51 \times 51(1 \times$ $\left.10^{-5} \sim 2 \times 10^{-4}\right)$ and $51 \times 51\left(1 \times 10^{-6} \sim 2 \times 10^{-4}\right)$ are also less than $2 \%$. Therefore, the computations with grid distribution of $51 \times$ $51\left(1 \times 10^{-5} \sim 2 \times 10^{-4}\right)$ are considered to be sufficiently accurate to describe the flow and heat transfer in an inclined rectangular duct. The local Nusselt number and friction factor were found to agree within $2 \%$. The above program tests indicate that the adopted solution methods are suitable for the present study.

\section{RESULTS AND DISCUSSION}

The results of this study are presented for air flowing in an inclined rectangular duct over a certain range of governing parameters. The Prandtl number is set to be 0.7 . The wall Reynolds number varies from -2 (injection) to 2 (suction), and the aspect ratio is set to be $0.2,0.5,1,2,5$, respectively. The modified Rayleigh number varies from 0 to $2 \times 10^{5}$ and the mixed convection parameter is set to be $0,50,100,150$, and 200. The typical case is set $\gamma=1, \Omega=100$ and $\mathrm{Ra}^{*}=5 \times 10^{4}$. The bulk temperature, circumferentially averaged wall temperature, local averaged friction factor and Nusselt number are determined from the calculated velocity and temperature fields. Both UHF and UWT cases were examined.

\section{Uniform Heat Flux Case}

Figure 2 presents the effects of wall transpiration on axial

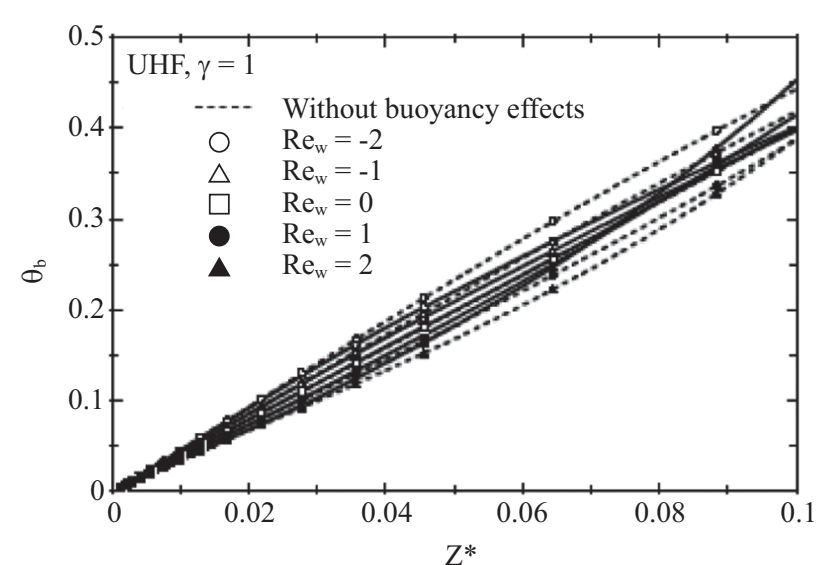

(a)

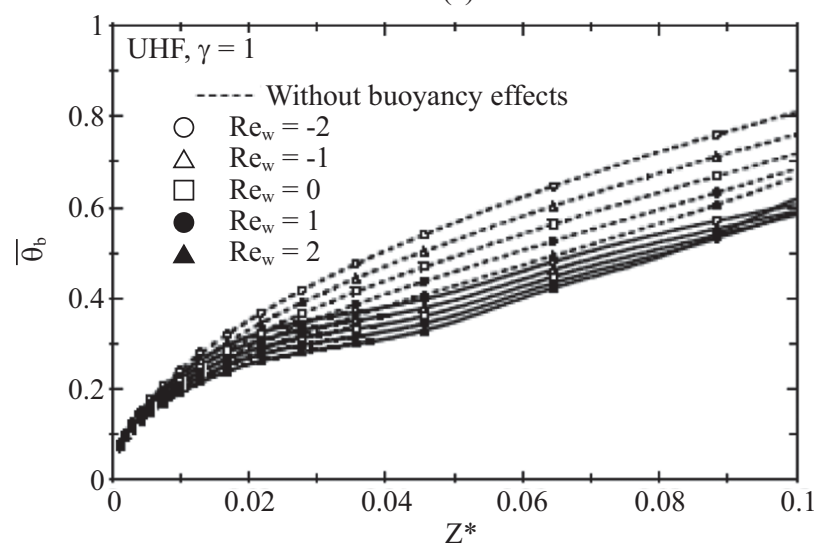

(b)

Fig. 2. Effect of wall Reynolds number on the (a) bulk temperature and, (b) average wall temperature distributions along the axial direction with uniform heat flux case.

distributions of bulk temperature and averaged wall temperature in an inclined rectangular duct. The modified Raleigh number is $5 \times 10^{4}$. The data without buoyancy effects (dashed curves) are also presented for comparison. Apparently, $\bar{\theta}_{w}$ without considering buoyancy effect is higher than that with buoyancy effect. The buoyancy effect on $\theta_{b}$ depends on the transpiration condition. It is also noted that the buoyancy effect is negligible near the entrance region. It is observed that $\theta_{b}$ without considering buoyancy effect is higher than that with buoyancy effect for suction case $\left(\operatorname{Re}_{\mathrm{w}}>0\right)$, while in the case of wall injection $\left(\operatorname{Re}_{\mathrm{w}}<0\right)$, the trend is reversed. This is because the buoyancy induced secondary flow carried the heat to and out of the fluid with injection and suction conditions. It is also found that $\theta_{b}$ and $\bar{\theta}_{w}$ decrease with increasing $\operatorname{Re}_{\mathrm{w}}$. This indicates that transpiration flow rate raises $\theta_{b}$ and $\bar{\theta}_{w}$ for injection and lowers $\theta_{b}$ and $\bar{\theta}_{w}$ for suction. Since the fluid is heated when entering through the wall, higher injection rate raises bulk temperature and by turn result in higher wall temperature to maintain uniform heat flux. Hence higher wall temperature distribution is found for higher injection rate. For 


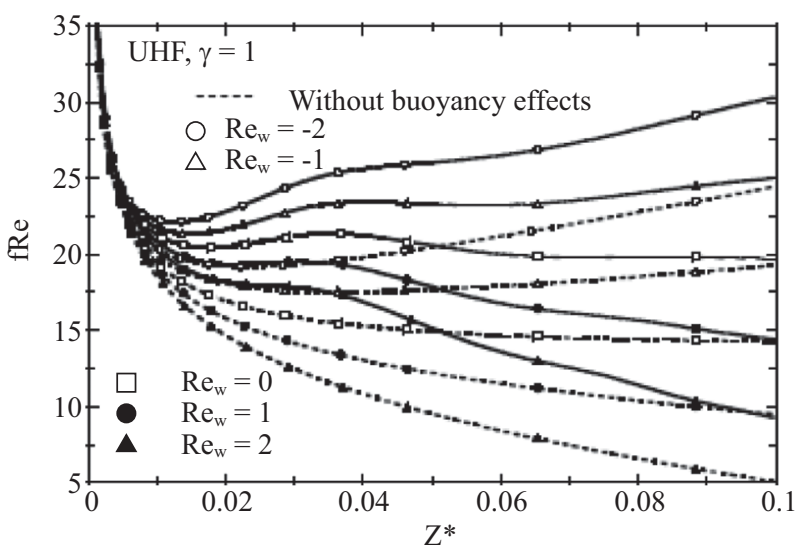

(a)

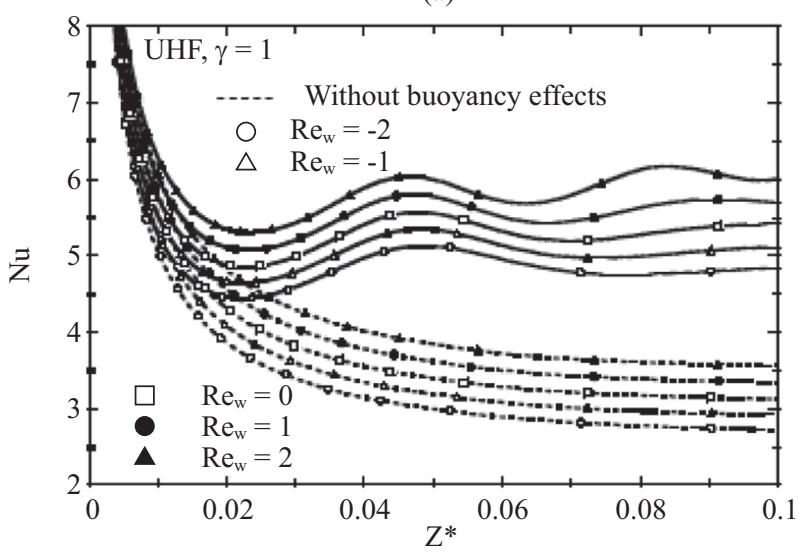

(b)

Fig. 3. Effect of wall Reynolds number on the (a) friction factor and, (b) Nusselt number distributions along the axial direction with uniform heat flux case.

the case of wall suction $\left(\operatorname{Re}_{\mathrm{w}}>0\right)$, the trend is reversed. Higher suction rate causes lower $\theta_{b}$ and $\bar{\theta}_{w}$ in the entrance region. But in the further downstream region, transverse conduction balances the suction thermal flow and gives rise to more rapid temperature rise. Hence the crossover of curves is found in both plots. Additionally, buoyancy effect on wall temperature is more apparent than that on bulk temperature.

The effects of $\mathrm{Re}_{\mathrm{w}}$ on axial distributions of circumferentially averaged friction factor and Nusselt number are shown in Fig. 3. Again, the dashed lines denote the results without buoyancy. It is found that the buoyancy has negligible effect on the friction factor in the very inlet $\left(\mathrm{Z}^{*}<0.01\right)$. It then augments the friction factor in the further downstream region for both wall injection and suction. Apparently, the buoyancy effect enhances the heat transfer rate. It is also seen that the friction factor is increased by decreasing $\mathrm{Re}_{\mathrm{w}}$. This suggests that mass injection results in higher friction factor since the mainstream is accelerated. For wall injection, the friction factor axially declines and reaches a local minimum due to the entrance effect and then rise in the further downstream region. For wall suction, the mass extraction causes further decay of fRe along the duct. It is noted that the Nusselt number is also

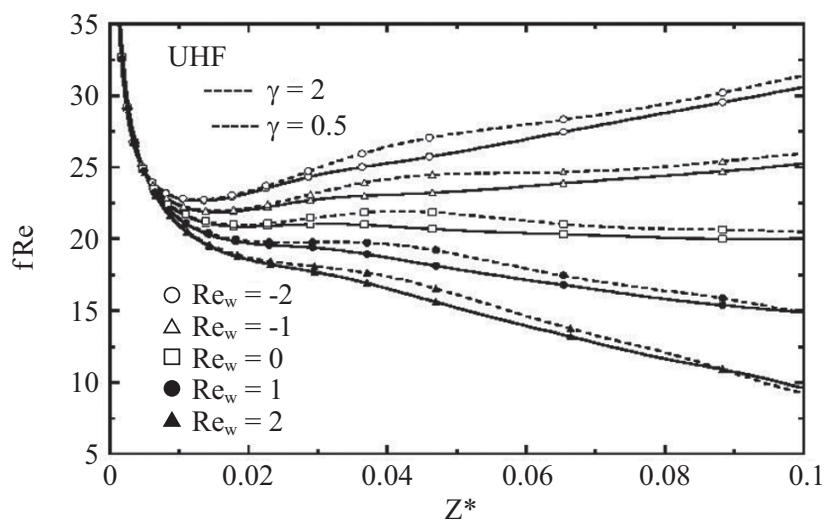

(a)

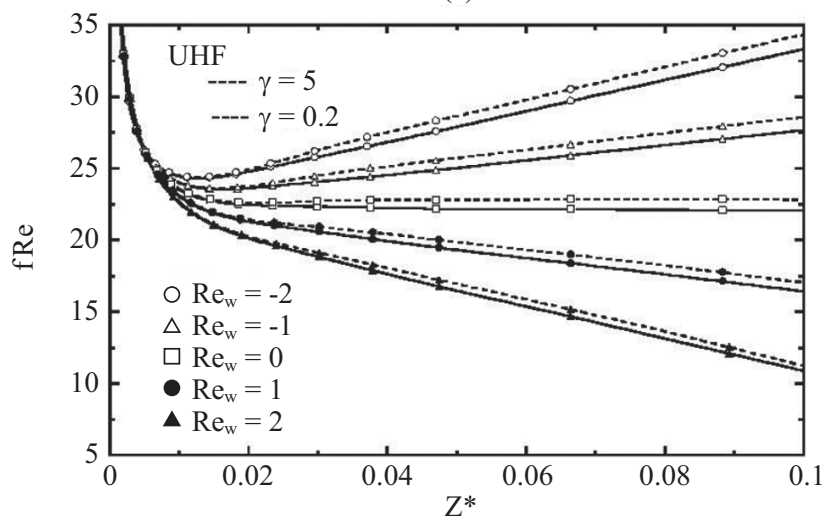

(b)

Fig. 4. Effect of wall Reynolds number on the friction factor distributions along the axial direction with uniform heat flux case for various aspect ratios.

increased with increasing $\mathrm{Re}_{\mathrm{w}}$ in Fig. 3(b). This is due to the lower temperature difference between wall and bulk fluid for suction case. It is interesting to see that results with buoyancy effects show fluctuation along the duct. This is due to the secondary flow resulted from the inclination of the duct. It is also noticed that the fluctuation increases as $\mathrm{Re}_{\mathrm{w}}$ increases. Obviously, the increasing fluctuation is resulted from the suction mass flow rate.

Figures 4 and 5 present the effects of wall transpiration on local averaged friction factor and Nusselt number, respectively, with different aspect ratios. In comparison with Fig. 3 for all aspect ratios, it is found that these profiles are similar with the same trend for various aspect ratios. In detail comparison of Figs. 3(a) and 4, it reveals that higher friction factor is obtained for larger $\gamma$ as $\gamma>1$, and for smaller $\gamma$ as $\gamma<1$. This indicates that a cross section close to square results in lower friction factor. Detailed inspection also shows that a slender channel $(\gamma<1)$ give rise to slightly higher fRe than a wider one $(\gamma>1)$. It suggests that slender channel results in thermal buoyancy flows stronger than wider one. In detail comparison of Figs. 3(b) and 5, lower Nusselt numbers can be achieved for cross section close to square. In addition, it is clear that the channel with slender or wider cross sections decreases the heat transfer fluctuation along the duct. 


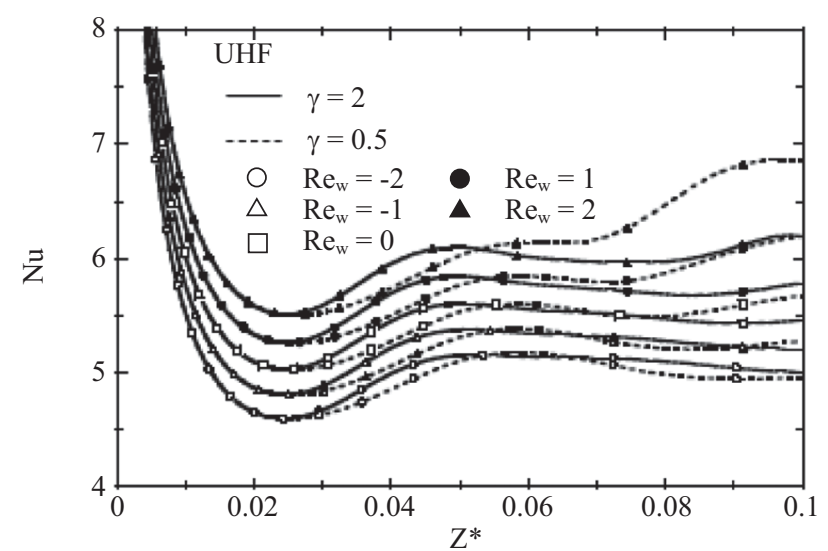

(a)

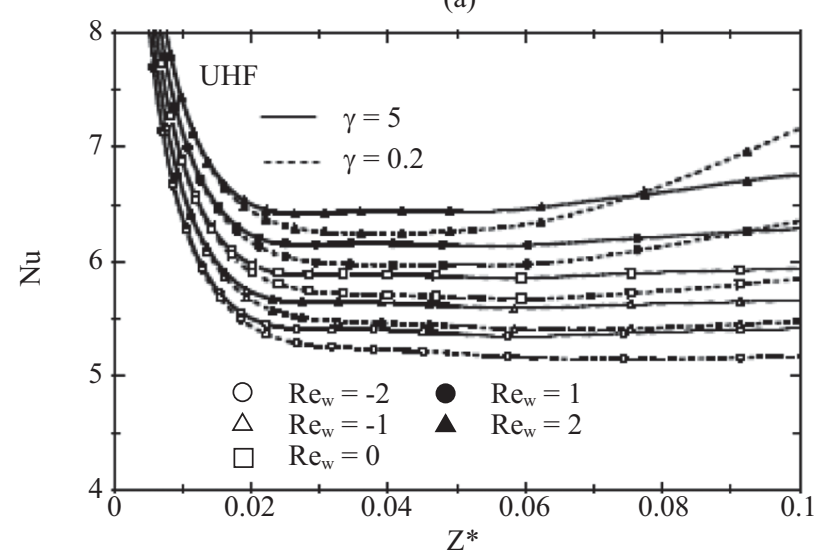

(b)

Fig. 5. Effect of wall Reynolds number on the Nusselt number distributions along the axial direction with uniform heat flux case for various aspect ratios.

The axial distributions of local averaged friction factor and Nusselt number for various modified Rayleigh Numbers are shown in Fig. 6 with both injection and suction cases. According to the definition of modified Rayleigh number, the value of $R a^{*}$ close to zero indicates highly forced convection and the buoyancy effect decreases as inclination angle increases. It is clearly seen that friction factor of the injection case is larger than that of the suction case for various $R a^{*}$, while the heat transfer shows the opposite trend. This can be easily understood that the friction factor increases and heat transfer reduced as the cold working fluid injected into the inclined duct. It is found that the friction factor and heat transfer increases as the modified Rayleigh number increases as $Z^{*}<0.06$, for both injection and suction cases. It is also noted that $R a^{*}$ has negligible effects for $Z^{*}<0.01$ and $\mathrm{Ra}^{*}<1 \times$ $10^{4}$. A further observation reveals that the curves branch out from those of forced convection for $\mathrm{Ra}^{*}<1 \times 10^{4}$. However, the friction factor for injection flow shows a local minimum, which is resulted from the combination of entrance and buoyancy effects. Fluctuations are observed for results with higher $R a^{*}$ due to unstable secondary flow.

Effects of mixed convection parameter on axial distribu-

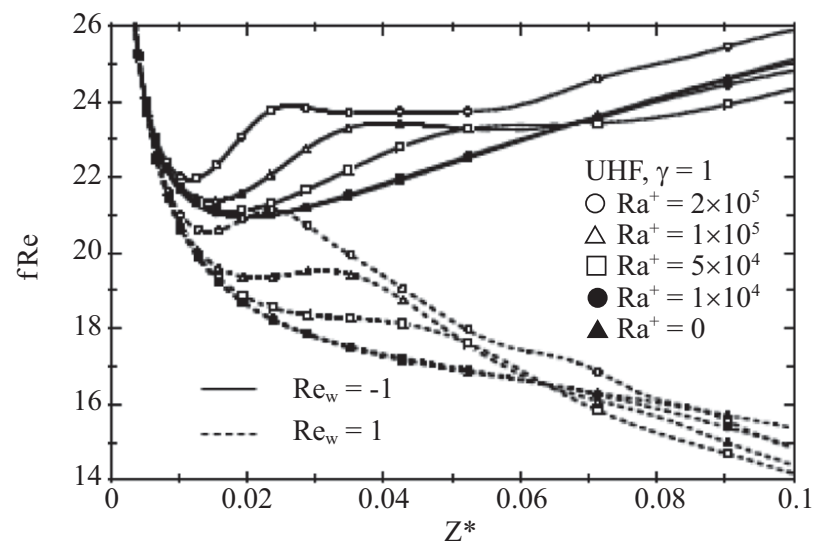

(a)

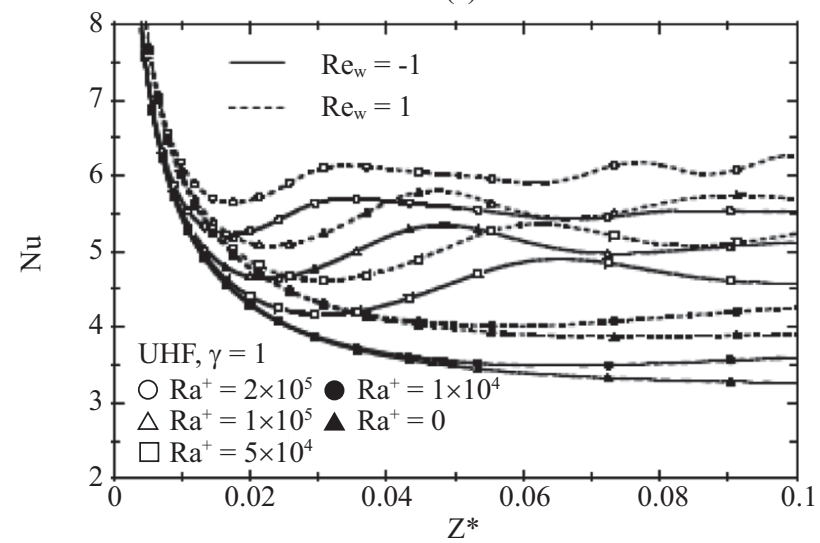

(b)

Fig. 6. Effect of modified Rayleigh number on (a) friction factor and, (b) the Nusselt number distributions along the axial direction with uniform heat flux case for injection and suction conditions.

tions of local averaged friction factor and Nusselt number are presented in Fig. 7. As aforementioned, $\Omega$ is a function composed of Rayleigh number, Reynolds number, and inclination angle. It is observed from Fig. 7(a) that both friction factor and Nusselt number are increased with increasing $\Omega$. This implies that increasing inclination angle contributes more buoyancy convection in axial direction and results in higher fRe and heat transfer. The value of zero indicates horizontal channel and give rise to the lowest fRe. The inclination angle enhances axial buoyancy and reduces the difference between wall temperature and bulk temperature. This by turn gradually augments Nusselt number along the duct. It is also noted that the fluctuation for Nusselt number is higher for larger $\Omega$. Apparently, the fluctuation is resulted from the inclination angle.

\section{Uniform Wall Temperature}

In the following, the case of uniform wall temperature (UWT) is considered. Figure 8 shows the axial distributions of local averaged friction factor and Nusselt number with various $\mathrm{Re}_{\mathrm{w}}$. By comparing Fig. 8 with Fig. 3, it reveals that the trend is the same for Figs. 8 and 3. However, the friction factor is higher in the entrance region. This is due to more 


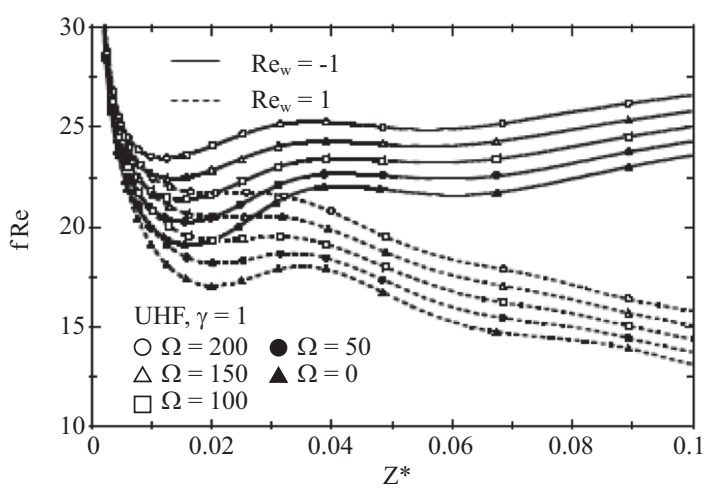

(a)

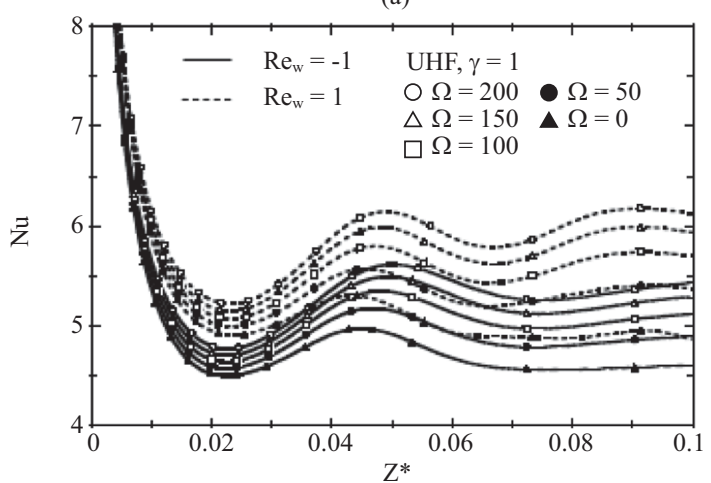

(b)

Fig. 7. Effect of modified convection parameter on (a) friction factor and, (b) the Nusselt number distributions along the axial direction with uniform heat flux case for injection and suction conditions.

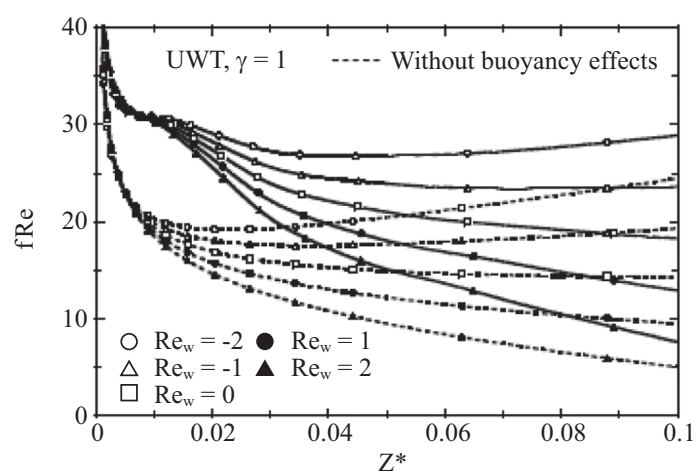

(a)

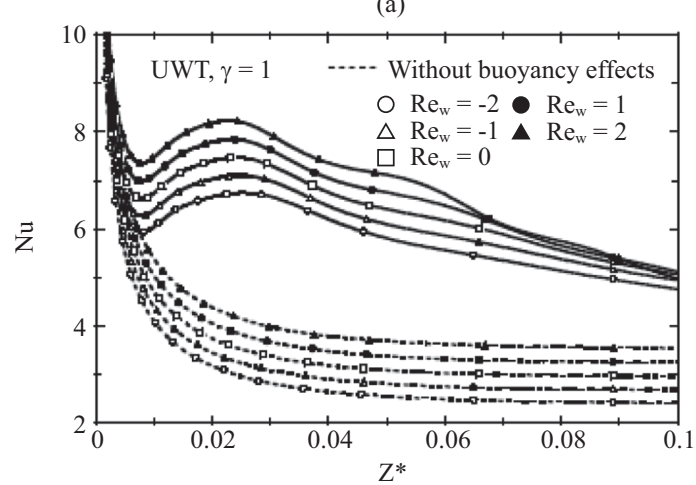

(b)

Fig. 8. Effect of wall Reynolds number on the (a) friction factor and, (b) Nusselt number distributions along the axial direction with uniform wall temperature case.

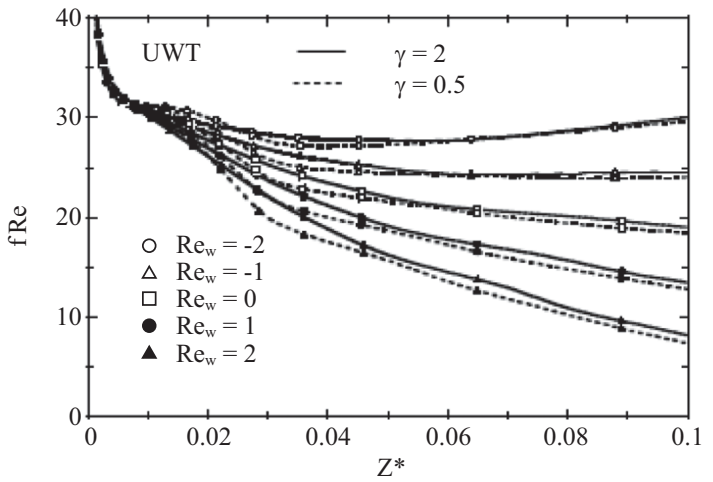

(a)

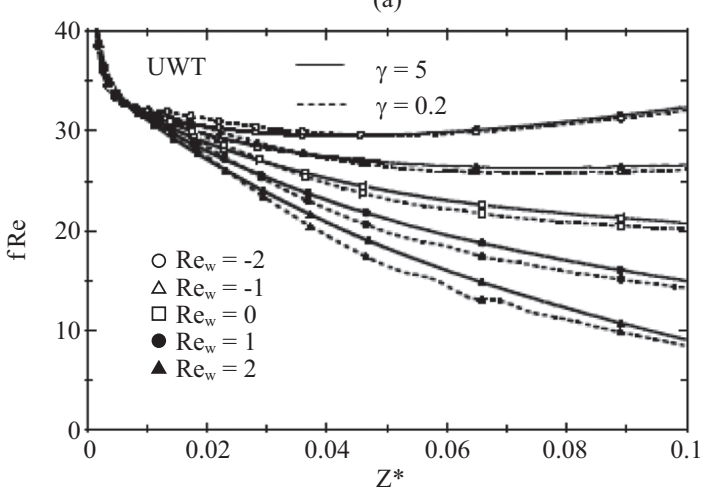

(b)

Fig. 9. Effect of wall Reynolds number on the friction factor distributions along the axial direction with uniform wall temperature case for various aspect ratios.

significant buoyancy in UWT than in UHF. It is found in Fig. 8(b) that the Nusselt number decreases rapidly to a local minimum and reaches a maximum. The local minimum and maximum are because of the entrance effect and the local secondary flow intensity. The Nusselt number then decreases monotonically along the axial direction and converges together for various $\mathrm{Re}_{\mathrm{w}}$. The heat transfer decreases along the duct due to bulk temperature approaching wall temperature. In addition, the Nusselt number is larger than that for UHF case for the same $\mathrm{Re}_{\mathrm{w}}$. This is due to the fact that the difference between bulk temperature and wall temperature are higher for UWT case.

The effects of wall transpiration on axial distributions of local averaged fRe and Nusselt number for various aspect ratios are shown in Figs. 9 and 10, respectively. It is interesting in Fig. 9 to see that a wider channel results in slight higher fRe than a slender one. This phenomenon is contrast to that in UHF case. It should be noted that the friction factor for UWT is higher than that for UHF in the entrance region. This is caused by the larger temperature difference, which resulted in larger buoyancy flow. In Fig. 10, it is observed that $\mathrm{Nu}$ is significantly affected by the orientation of the duct crosssection. Wider channels $(\gamma>1)$ result in comparative smooth and lower heat transfer, while slender channels $(\gamma<1)$ result in higher and fluctuating heat transfer. This is due to the fact that slender channels have stronger secondary flows by thermal 


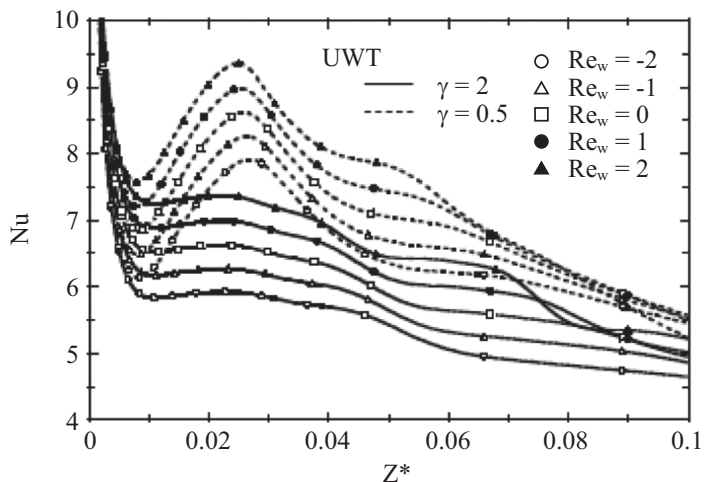

(a)

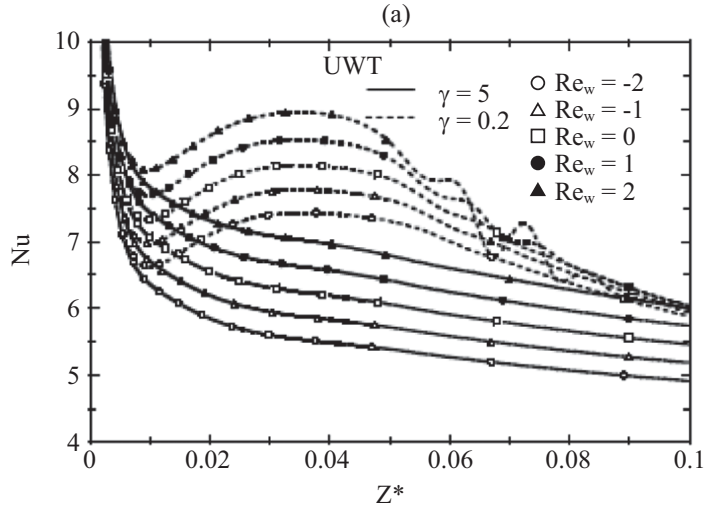

(b)

Fig. 10. Effect of wall Reynolds number on the Nusselt number distributions along the axial direction with uniform wall temperature case for various aspect ratios.

buoyancy. In detailed comparison of Fig. 5(b) with Fig. $10(\mathrm{~b})$, it is noted that the trends are opposite. It is believed that for the UHF cases, the average temperature difference between the duct wall temperature and bulk fluid temperature is increased to maintain the uniform wall heat flux.

Figure 11 describes the effects of modified Raleigh number on the axial distributions of local averaged friction factor and Nusselt number. It is shown in Fig. 11(a) that the friction factor converges together at the downstream for different $R a^{*}$. Also, the converged value for injection case is higher than that for suction case. However, there is no clear relation between $R a^{*}$ and fRe due to the interaction between inclination and buoyancy effect. As for the concern of heat transfer, it is discovered in Fig. 11(b) that the Nu increases with increasing $R a^{*}$. It is observed that $\mathrm{Nu}$ with higher modified Raleigh number presents higher branch out from the forced convection one in the region of $0.01<Z^{*}<0.06$. In addition, the influence of $R a^{*}$ begins to decay in the region of $Z^{*}>0.06$. In comparison with Fig. 6(b), Nu is larger for UWT in entrance region, while $\mathrm{Nu}$ is smaller in the down stream. This is because the temperature difference between wall and bulk fluid is higher at the entrance region for UWT case, while it becomes smaller at the down stream.

Figure 12 shows the effects of mixed convection parameter on axial distributions of local averaged friction factor and

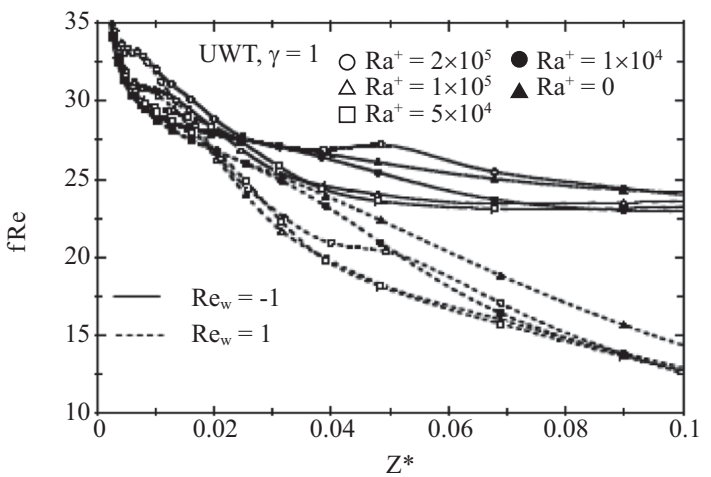

(a)

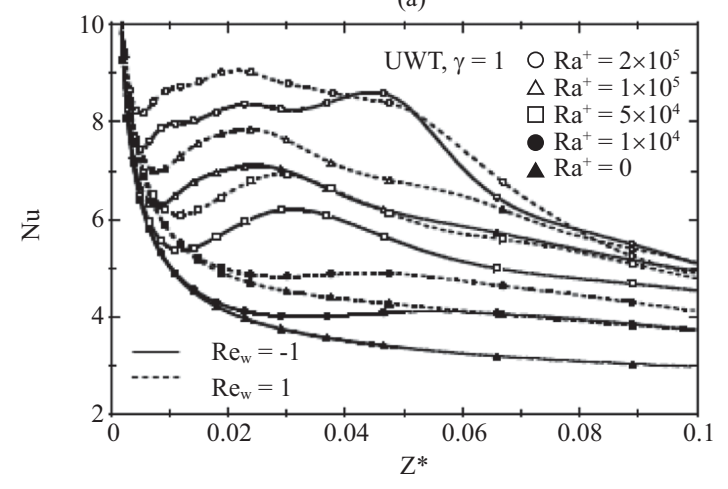

(b)

Fig. 11. Effect of modified Rayleigh number on (a) friction factor and, (b) the Nusselt number distributions along the axial direction with uniform wall temperature case for injection and suction conditions.

Nusselt number. According to the definition of $\Omega$, it increases as inclination angle increases. The mixed convection parameter has significant influence on the friction factor in the entrance region at $\mathrm{Z}^{*}<0.03$. It is observed that the friction factor increases with increasing $\Omega$. This indicates that the friction factor increases as inclination angle increases. However, it is also noted that the friction factor converges together at the downstream for different values of $\Omega$. This indicates that the effects of $\Omega$ are restricted in the entrance region for UWT since the thermal buoyancy decays along the duct. It is found in Fig. 12(b) that the influence of $\Omega$ on $\mathrm{Nu}$ is insignificant. However, it does show the trend that the $\mathrm{Nu}$ increases as $\Omega$ increases in the entrance region $\left(Z^{*}<0.03\right)$. In a closer observation for the position of local minimum, it depicts that the distance of local minimum from the inlet increases as $\Omega$ increases. The local minimum is the result of interaction between buoyancy and entrance effect. The buoyancy effect is higher for larger inclination angle, which causes a larger distance of local minimum from the inlet.

\section{CONCLUSION}

The effects of wall transpiration on mixed convective flow and heat transfer in inclined ducts have been studied numerically. A vorticity-velocity method and a marching technique 


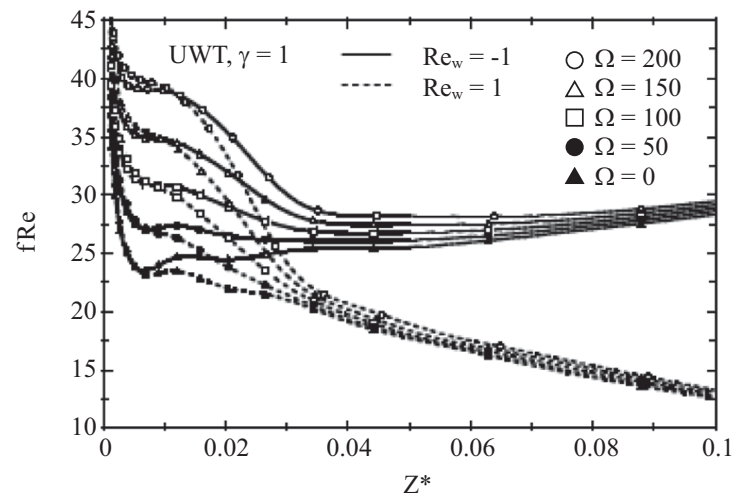

(a)

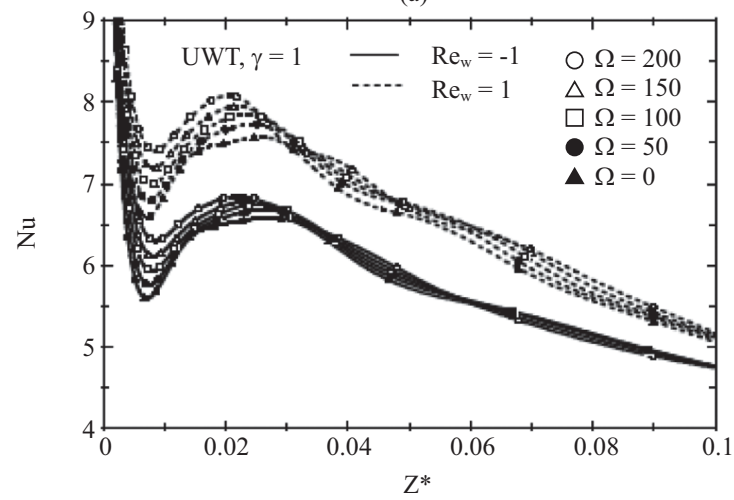

(b)

Fig. 12. Effect of modified convection parameter on (a) friction factor and, (b) the Nusselt number distributions along the axial direction with uniform wall temperature case for injection and suction conditions.

have been employed to solve the three dimensional problem. The effects of wall Reynolds number, aspect ratio, modified Raleigh number, and mixed convection factor on the averaged local friction factor and Nusselt number are systematically studied. Brief summaries of the major results are listed in the following:

1. For both UHF and UWT cases, the local averaged fRe is increased with decreasing $\mathrm{Re}_{\mathrm{w}}$; while the local averaged $\mathrm{Nu}$ is increased with increasing $\mathrm{Re}_{\mathrm{w}}$. Buoyancy effects raise the values of fRe and $\mathrm{Nu}$. In UWT case, the augmentation on $\mathrm{Nu}$ mainly takes place in the entrance region.

2. As inclination angle increases, the buoyancy effect increases as well which causes an unstable secondary flow resulting the fluctuation in the distribution of friction factor and $\mathrm{Nu}$.

3. In UHF case, a slender channel results in higher fRe than a wider channel. In UWT case, the situation is reversed.

4. In the UHF case, $\mathrm{Nu}$ is increased with increasing modified Raleigh number through out channel; while in the UWT case, the effects of modified Raleigh number are mainly restricted in the entrance region.

5. Both fRe and $\mathrm{Nu}$ are increased with increasing mixed convection parameter through out the channel in the UHF

case. But in the UWT case, the augmentation on fRe and $\mathrm{Nu}$ is significant in the entrance region.

\section{ACKNOWLEDGMENTS}

The authors would like to acknowledge the financial support of the present work by the National Science Council, R.O.C. through the contract NSC93-2212-E211-011 and NSC952221-E149-012. The support from Technology and Science Institute of Northern Taiwan is also acknowledged.

\section{NOMENCLATURE}

A

$a, b$

$c_{\mathrm{p}}$

$\mathrm{D}_{\mathrm{e}} \quad$ equivalent hydraulic diameter, $2 a b /(a+b)$

$f \quad$ friction factor, $2 \tau_{\mathrm{w}} /\left(\rho_{\mathrm{o}} \mathrm{w}_{\mathrm{o}}{ }^{2}\right)$

Gr Grashof number, $\mathrm{g} \beta \Delta \mathrm{TD}_{\mathrm{e}}{ }^{3} / v^{2}$

$\bar{h} \quad$ circumferentially average heat transfer coefficient $\left(\mathrm{Wm}^{-2} \mathrm{~K}^{-1}\right)$

$k \quad$ thermal conductivity $\left(\mathrm{Wm}^{-1} \mathrm{~K}^{-1}\right)$

$\mathrm{M}, \mathrm{N}$ number of the finite difference divisions in the $\mathrm{X}$ and $\mathrm{Y}$ directions, respectively

$\mathrm{n} \quad$ direction coordinate normal to the duct wall

$\bar{p} \quad$ cross-sectional mean pressure $(\mathrm{kPa})$

$\bar{P}$

$p^{\prime} \quad$ perturbation term about mean pressure $(\mathrm{kPa})$

$P^{\prime} \quad$ dimensionless perturbation pressure

$\mathrm{Pe} \quad$ Peclet number, $\mathrm{Pr} \bullet \mathrm{Re}$

Pr Prandtl number, $v / \alpha$

$\mathrm{Ra} \quad$ Rayleigh number, $\mathrm{Pr} \cdot \mathrm{Gr}$

$\mathrm{Ra}^{*} \quad$ modified Rayleigh number, $\mathrm{Ra} \times \cos \Theta$

Re Reynolds number, $\mathrm{w}_{\mathrm{o}} \mathrm{D}_{\mathrm{e}} / \mathrm{v}$

S perimeter of duct cross section, $2(a+b)$

$\mathrm{T} \quad$ temperature $(\mathrm{K})$

$\mathrm{U}, \mathrm{V}, \mathrm{W}$ dimensionless velocity components in the $\mathrm{X}, \mathrm{Y}$, and $\mathrm{Z}$ directions, respectively

$\mathrm{u}, \mathrm{v}, \mathrm{w} \quad$ velocity components in the $\mathrm{x}, \mathrm{y}$, and $\mathrm{z}$ directions, respectively $\left(\mathrm{ms}^{-1}\right)$

$\mathrm{W}_{\mathrm{o}} \quad$ uniform velocity at the inlet, $\mathrm{m} / \mathrm{s}$

$\mathrm{X}, \mathrm{Y}, \mathrm{Z}$ dimensionless rectangular coordinate, $\mathrm{X}=\mathrm{x} / \mathrm{D}_{\mathrm{e}}, \mathrm{Y}$ $=\mathrm{y} / \mathrm{D}_{\mathrm{e}}, \mathrm{Z}=\mathrm{z} /\left(\mathrm{D}_{\mathrm{e}} \cdot \mathrm{Re}\right)$

$\mathrm{Z}^{*} \quad$ dimensionless $\mathrm{z}$-direction coordinate, $\mathrm{z} /(\mathrm{Pr} \cdot \mathrm{Re} \bullet$ $\left.\mathrm{D}_{\mathrm{e}}\right)=\mathrm{Z} / \mathrm{Pr}$

$\mathrm{x}, \mathrm{y}, \mathrm{z} \quad$ rectangular coordinate system $(\mathrm{m})$

Greek symbols

$\alpha \quad$ thermal diffusivity $\left(\mathrm{m}^{2} \mathrm{~s}^{-1}\right)$

$\beta \quad$ coefficient of thermal expansion $(1 / \mathrm{K})$

$\gamma \quad$ aspect ratio of a rectangular duct, $b / a$

$\theta \quad$ dimensionless temperature, $\left(T-T_{o}\right) /\left(T_{w}-T_{o}\right)$ 
$\Theta \quad$ inclination angle

$v \quad$ kinematic viscosity $\left(\mathrm{m}^{2} \mathrm{~s}^{-1}\right)$

$\rho \quad$ density $\left(\mathrm{kgm}^{-3}\right)$

$\tau_{\mathrm{w}} \quad$ wall shear stress, $\mathrm{kPa}$

$\Omega \quad$ mixed convection parameter

$\xi$ dimensionless vorticity in the axial direction, $\partial \mathrm{U} / \partial \mathrm{Y}-\partial \mathrm{V} / \partial \mathrm{X}$

\section{REFERENCES}

1. Berman, A. S., "Laminar flow in channels with porous walls," Journal of Applied. Physics, Vol. 24, pp. 1232-1235 (1953).

2. Erdoğan, M. E. and İmrak, C. E., "The effects of the sidewalls on the flow of a second grade fluid in ducts with suction and injection," International Journal of Non-Linear Mechanics, Vol. 42, pp. 765-772 (2007).

3. Feddaoui, M., Belahmidi, E., Mir, A., and Bendou, A., "Numerical study of the evaporative cooling of liquid film in laminar mixed convection tube flows," International Journal of Thermal Sciences, Vol. 40, pp. 10111020 (2001).

4. Feddaoui, M., Mir, A., and Belahmidi, E., "Cocurrent turbulent mixed convection heat and mass transfer in falling film of water inside a vertical heated tube," International Journal of Heat and Mass Transfer, Vol. 46, pp. 3497-3509 (2003).

5. Hammou, Z. A., Benhamou, B., Galanis, N., and Orfi, J., "Laminar mixed convection of humid air in a vertical channel with evaporation or condensation at the wall," International Journal of Thermal Sciences, Vol. 43, pp. 531-539 (2004).

6. Huang, C. C. and Lin, T. F., "Numerical simulation of transitional aiding mixed convection air flow in a bottom heated inclined rectangular duct," International Journal of Heat and Mass Transfer, Vol. 39, pp. 1697-1710 (1996).

7. Huang, C. C., Yan, W. M., and Jang, J. H., "Laminar mixed convection heat and mass transfer in vertical rectangular ducts with film evaporation and condensation," International Journal of Heat and Mass Transfer, Vol. 48, pp. 1772-1784 (2005).

8. Ishak , A., Nazar, R., and Pop, I., "The effects of transpiration on the boundary layer flow and heat transfer over a vertical slender cylinder," International Journal of Non-Linear Mechanics, Vol. 42, pp. 1010-1017 (2007).

9. Jang, J. H., Yan, W. M., and Huang, C. C., "Mixed convection heat transfer enhancement through film evaporation in inclined square ducts," International Journal of Heat and Mass Transfer, Vol. 48, pp. 2117-2125 (2005).

10. Lee, K. T. and Yan, W. M., "Mixed convection heat transfers in horizontal rectangular ducts with wall transpiration effects," International Journal of Heat and Mass Transfer, Vol. 41, pp. 411-423 (1998).

11. Lin, J. N., Chou, F. C., Yan, W. M., and Tzeng, P. Y., "Combined buoyancy effects of thermal and mass diffusion on laminar forced convection in the thermal entrance region of horizontal square channels," Canadian Journal of Chemical Engineering, Vol. 79, pp. 681-689 (1992)

12. Lin, J. N., Tzeng, P.Y., Chou, F. C., and Yan, W. M., "Convective instability of heat and mass transfer for laminar forced convection in the thermal entrance region of horizontal rectangular channels," International Journal of Heat and Fluid Flow, Vol. 13, pp. 250-280 (1992).

13. Mahaney, H. V., Incropera, F. P., and Ramadhyani, S., "Development of laminar mixed convection flow in a horizontal rectangular duct with uniform bottom heating," Numerical Heat Transfer, Vol. 12, pp. 137-155 (1987).

14. Oyewola, O. M., "Streamwise variations of higher-order turbulence statistics in a turbulent boundary layer subjected to localise wall suction," International Journal of Mechanical Sciences, Vol. 48, pp. 1163-1171 (2006).

15. Pederson, R. J. and Kinney, R. B., "Entrance-region heat transfer for laminar flow in porous tubes," International Journal of Heat and Mass Transfer, Vol. 14, pp. 159-161 (1971).

16. Raithby, G. D., "Laminar heat transfer in the thermal entrance region of circular tubes and two-dimensional rectangular ducts with wall suction and injection," International Journal of Heat and Mass Transfer, Vol. 14, pp. 224-243 (1971).

17. Raithby, G. D. and Knudsen, D. C., "Hydrodynamic development in a duct with suction and blowing," Journal of Applied Mechanics, Vol. 96, pp. 896-902 (1974).

18. Ramakrishna, K., Rubin, S. G., and Khosla, P. K., "Laminar natural convection along vertical square ducts," Numerical Heat Transfer, Vol. 5, pp. 59-79 (1982).

19. Roche, P. J., Computational Fluid Dynamics, Reinhold, New York, pp. 61-64 (1971).

20. Sorour, M. M., Hassab, M. A., and Estafanous, S., "Developing laminar flow in a semiporous two-dimensional channel with nonuniform transpiration," International Journal of Heat and Fluid Flow, Vol. 8, pp. 44-54 (1987).

21. Terrill, R. M., "An exact solution for flow in a porous pipe," Journal of Applied Mathematical Physics, Vol. 33, pp. 547-552 (1982).

22. Terrill, R. M., "Laminar flow in a porous tube," Journal of Fluids Engineering, Vol. 105, pp. 303-306 (1983).

23. Wang, M., Tsuji, T., and Nagano, Y., "Mixed convection with flow reversal in the thermal entrance region of horizontal and vertical pipes," International Journal of Heat and Mass Transfer, Vol. 37, pp. 2305-2319 (1994).

24. Yan, W. M., "Turbulent mixed convection heat and mass transfer in a wetted channel," ASME Journal of Heat Transfer, Vol. 117, pp. 229-233 (1995).

25. Yan, W. M., "Transport phenomena of developing laminar mixed convection heat and mass transfer in inclined rectangular ducts," International Journal of Heat and Mass Transfer, Vol. 38, pp. 2905-2914 (1995).

26. Yan, W. M., "Effects of wall transpiration on mixed convection in a radial outward flow inside rotating ducts," International Journal of Heat and Mass Transfer, Vol. 38, pp. 2333-2342 (1995).

27. Yan, W. M., "Developing flow and heat transfer in radially rotating rectangular ducts with wall-transpiration effects," International Journal of Heat and Mass Transfer, Vol. 37, pp. 1465-1473 (1994).

28. Yan, W. M. and Soong, C. Y., "Mixed convection flow and heat transfer between two co-rotating porous disks with wall transpiration," International Journal of Heat and Mass Transfer, Vol. 40, pp. 773-784 (1997). 